\title{
ANALISIS NILAI TAMBAH BUNGA POTONG KRISAN PADA NINGSIH FLORIST DI KOTA TOMOHON
}

\author{
Merry Shenly Tololiu \\ Paulus A. Pangemanan \\ Caroline B. D. Pakasi
}

\begin{abstract}
The objective of this research is to analyze the value added of chrysanthemum flowers on Ningsih Florist. The research was conducted for 4 months in Kakaskasen II, Tomohon City. The data were obtained by direct interviews with business owners and then analyzed by descriptive quantitatively. The research results showed that acceptance ningsih florist business where the average monthly spending \pm 5.148 stalk of chrysanthemum flowers with the acceptance of all the flower arrangements, namely IDR. 66,040,000.00. Enterprises chrysanthemum flower arrangements by Ningsih Florist as a whole can benefit and deserves to be developed. It is based on the analysis of the value added that gross value added amounted to IDR. 16,729,984.20, net value added IDR. 16,683,734.20, value added every feedstock IDR. 3249.80 / stalk. The calculated value added that each item is flower corsage flower arrangement has the value added IDR. 4,424 / item, bouquets IDR. 212249 / item, flower table IDR. 914 / item, floral wreaths IDR. 8,615 / item, and flower board IDR. $115140 /$ item.
\end{abstract}

Key words: value added analysis, chrysanthemum flowers, Kakaskasen II, Tomohon City

\begin{abstract}
ABSTRAK
Penelitian ini bertujuan untuk menganalisis nilai tambah bunga krisan pada ningsih florist. Penelitian dilaksanakan selama 4 bulan yang berlokasi di Kelurahan Kakaskasen II Kota Tomohon. Data diperoleh melalui wawancara langsung dengan pemilik usaha lalu dianalisis secara deskriptif kuantitatif. Hasil menunjukkan penerimaan usaha ningsih florist dimana rata-rata setiap bulannya menghabiskan \pm 5.148 tangkai bunga krisan dengan penerimaan dari seluruh rangkaian bunga yaitu Rp. 66.040.000,00. Usaha rangkaian bunga krisan pada Ningsih Florist secara keseluruhan dapat memperoleh keuntungan dan layak untuk dikembangkan. Hal ini berdasarkan hasil analisis nilai tambah,dalam satu kali produksi pada bulan April 2015, yang diperoleh yaitu nilai tambah bruto Rp. 16.729.984,20, nilai tambah netto Rp. 16.683.734,20, nilai tambah per bahan baku Rp. 3.249,80/tgk. Adapun dihitung nilai tambah yang dimiliki setiap item rangkaian bunga yaitu bunga korsase memiliki nilai tambah Rp. 4.424/ item, bunga tangan Rp. 212.249/ item, bunga meja Rp. 914/ item, bunga krans Rp. 8.615/ item, dan bunga papan Rp. 115.140/ item.
\end{abstract}

Kata Kunci : Analisis Nilai Tambah, Bunga Krisan, Kelurahan Kakaskasen II, Kota Tomohon

\section{PENDAHULUAN}

\section{Latar Belakang}

Kecamatan Tomohon Utara memiliki potensi pengembangan komoditas krisan yang sangat mendukung sehingga krisan di kembangkan di daerah ini. Sentra utama pemasaran florikultura berada di Desa Kelurahan Kakaskasen II, Kecamatan
Tomohon Utara dengan 12 kios florikultura yang menjual bunga potong dan daun potong maupun rangkaian, diantaranya adalah Ningsih Florist. Ningsih Florist yang dikelola oleh Ibu Ningsih Hamzah tersebut mulai berdiri sejak tahun 2007 yang kini memiliki tenaga kerja sebanyak 8 (delapan) orang. Selain menjual bunga krisan, Ningsih Florist juga menjual bunga anthurium, kirk lily, anyelir, florida beauty, peacock, mawar, dll. Tapi yang banyak 
dijualnya adalah bunga krisan. Sebanyak 8 (delapan) orang tenaga kerja Ningsih Florist digaji per hari dengan nominal gaji sesuai dengan keahlian masing-masing.

Dilihat dari keadaan usahanya, Ningsih Florist memproduksi rangkaian bunga setiap hari sesuai dengan pemesanan dan permintaan dari konsumen. Bunga krans, bunga korsase (bunga dada), dan bunga papan, merupakan beberapa rangkaian yang merupakan nilai tambah dari bunga krisan.

Istilah nilai tambah (value added) merupakan nilai yang ditambahkan pada suatu produk karena masuknya unsur pengolahan produk primer menjadi produk baru yang lebih tinggi nilai ekonomisnya setelah melalui proses pengolahan, maka akan memberikan nilai tambah karena dikeluarkan tenaga dan bahan tambahan ataupun biaya-biaya lainnya sehingga terbentuk harga baru yang lebih tinggi dan keuntungan lebih besar bila dibandingkan dengan harga tanpa melalui proses-proses tersebut. Dikarenakan hal demikian maka peneliti tertarik untuk mengadakan penelitian ini guna menganalisis nilai tambah yang dimiliki bunga krisan sebagai rangkaian bunga.

\section{Rumusan Masalah}

Berdasarkan latar belakang yang dikemukakan di atas, maka rumusan masalah dalam penelitian ini yaitu berapa besar nilai tambah bunga potong krisan pada Ningsih Florist?

\section{Tujuan Penelitian}

1. Tujuan dari penelitian ini adalah menganalisis nilai tambah bunga potong krisan pada Ningsih Florist.

\section{Manfaat Penelitian}

1. Bagi peneliti, dapat dijadikan sebagai pengetahuan tambahan mengenai apa yang dibahas dalam proposal penelitian ini dan untuk melengkapi persyaratan guna memperoleh gelar Sarjana Pertanian Universitas Sam Ratulangi Manado.

2. Bagi pengusaha, penelitian ini diharapkan dapat memberikan informasi mengenai nilai tambah yang diperoleh dari usaha yang dijalankan.
3. Bagi pihak lain, diharapkan hasil penelitian ini dapat berguna sebagai informasi tambahan.

\section{METODE PENELITIAN}

\section{Waktu dan Tempat Penelitian}

Penelitian ini berlangsung selama 4 (empat) bulan mulai bulan Februari hingga bulan Mei 2015. Pada tahap penelitian mulai dari tahap persiapan, pengumpulan data dan analisis data penyusunan laporan hasil. Penelitian ini dilaksanakan pada Ningsih Florist di Kota Tomohon.

\section{Metode Pengumpulan Data}

Data yang dikumpulkan dalam penelitian ini terdiri dari :

1. Data primer adalah data yang dikumpulkan dan diperoleh langsung dari sampel menggunakan daftar pertanyaan yang sudah dipersiapkan.

2. Data sekunder adalah data yang diperoleh dari instansi terkait di Dinas Pertanian dan berbagai media online selain dari berbagai buku dan literatur yang berkaitan dengan penelitian ini.

\section{Konsep Pengukuran Variabel}

1. Produk yang dihasilkan, meliputi :

a. Jenis rangkaian bunga, yaitu model dan maksud rangkaian bunga yang diproduksi (pcs).

b. Jumlah rangkaian bunga, yaitu banyaknya rangkaian bunga yang diproduksi per jenis rangkaian (pcs).

c. Harga jual per satuan jenis rangkaian bunga (Rp/pcs).

2. Tenaga kerja, meliputi :

a. Jumlah tenaga kerja, yaitu banyaknya tenaga kerja yang digunakan dalam kegiatan produksi (Orang).

b. Biaya tenaga kerja, yaitu biaya yang dikeluarkan untuk membayar tenaga kerja yang digunakan (upah per hari).

3. Bahan baku, meliputi :

a. Jumlah bahan baku, yaitu banyaknya jumlah bahan yang digunakan untuk menunjang kegiatan produksi (tgk).

b. Biaya bahan baku, yaitu biaya yang dikeluarkan untuk membeli bahan baku yang digunakan (Rp/tgk) 
4. Peralatan, meliputi :

a. Jumlah peralatan, yaitu banyaknya jenis dan jumlah peralatan yang digunakan dalam proses pembuatan rangkaian bunga

b. Biaya penyusutan peralatan, yaitu biaya yang dihitung melalui perbandingan nilai alat-alat yang digunakan pada keseluruhan proses produksi pada tahun tertentu dibandingkan dengan tahun sekarang yang diukur berdasarkan rupiah per tahun.

5. Penerimaan, yaitu perkalian antara jumlah produksi rangkaian bunga yang diperoleh dengan harga jual rangkaian bunga tersebut dinyatakan dalam satuan rupiah (Rp).

6. Biaya-biaya, yaitu jumlah seluruh biaya atau dana yang dikeluarkan pada awal usaha, selama proses produksi, dan pemasaran atau penjualan (Biaya Operasional) yang dinyatakan dalam satuan rupiah $(\mathrm{Rp})$, terdiri atas :

a. Biaya variabel yang meliputi biaya bahan baku, biaya tenaga kerja, dan biaya pemasaran/penjualan (biaya transportasi).

b. Biaya tetap yang meliputi biaya penyusutan peralatan, biaya pajak, biaya sewa bangunan, dan biaya listrik.

7. Bahan penolong, yaitu bahan-bahan yang digunakan dalam proses produksi yang termasuk input selain bahan baku misalnya dedaunan, peniti dan pita.

8. Nilai tambah, yaitu nilai yang ditambahkan pada suatu produk karena adanya pengolahan produk primer menjadi produk baru sehingga nilai ekonomisnya lebih tinggi.

Rumus perhitungan nilai tambah, yaitu :

a. Nilai tambah bruto

$$
\begin{aligned}
\mathrm{NTb} & =\mathrm{Na}-\mathrm{Ba} \ldots \ldots \ldots .(\mathrm{a}) \\
& =\mathrm{Na}-(\mathrm{Bb}+\mathrm{Bp}+\mathrm{Btk})
\end{aligned}
$$

Keterangan :

$\mathrm{NTb}=$ Nilai tambah bruto (Rp)

$\mathrm{Na}=$ Nilai produk akhir bunga krisan (Rp)

$\mathrm{Ba}=$ Biaya antara $(\mathrm{Rp})$

$\mathrm{Bb}=$ Biaya bahan baku bunga rangkai
$\mathrm{Bp}=$ Biaya bahan penolong bunga rangkai

Btk = Biaya tenaga kerja

b. Nilai Tambah Netto (NTn)

$\mathrm{NTn}=\mathrm{NTb}-\mathrm{NP}$

Nilai awal-nilai sisa

$N P=$

Keterangan :

NTn $=$ Nilai tambah netto $(\mathrm{Rp})$

$\mathrm{NTb}=$ Nilai tambah bruto (Rp)

$\mathrm{NP}=$ Nilai penyusutan $(\mathrm{Rp})$

c. Nilai Tambah per Bahan Baku

$\mathrm{NTbb}=\mathrm{NTb}: \Sigma \mathrm{bb}$

Keterangan :

$\mathrm{NTbb}=$ Nilai tambah per bahan baku yang digunakan $(\mathrm{Rp} / \mathrm{tk})$

$\mathrm{NTb}=$ Nilai tambah bruto (Rp)

$\Sigma$ bb = Jumlah bahan baku yang digunakan (tk)

\section{Analisa Data}

Data disajikan secara deskriptif kuantitatif dalam bentuk tabulasi. Analisa data kuantitatif meliputi : Nilai Tambah Bruto (NTb), Nilai Tambah Netto (NTn), Nilai Tambah per Bahan Baku (NTbb). Pengolahan data menggunakan alat bantu program Microsoft Excel.

Menurut Dewanti dalam Valentina (2009), metode analisis yang digunakan dalam menghitung nilai tambah (value added) adalah seperti pada Formula a,b, dan c.

\section{HASIL DAN PEMBAHASAN}

\section{Gambaran Umum Usaha Rangkaian Bunga Krisan}

\section{Sejarah Singkat Ningsih Florist}

Ningsih Florist merupakan salah satu kios florikultura yang menjual aneka rangkaian bunga di Kelurahan Kakaskasen Dua Kota Tomohon. Nama "Ningsih" dipilih sebagai nama kios Florikultura karena nama pemilik yaitu Ibu Ningsih Hamzah sendiri.

Produksi rangkaian bunga seperti bunga dada, bunga tangan, bunga meja, bunga krans, dan bunga papan, pada awalnya tidak terlalu banyak, maka dari itu produksi tidak dilakukan setiap hari. 


\section{Lokasi dan Keadaan Usaha}

Ningsih Florist berlokasi di Kelurahan Kakaskasen Dua Lingkungan IX Kota Tomohon. Lokasi ini merupakan tempat produksi sekaligus tempat tinggal pemilik.

\section{Struktur Organisasi}

Berdasarkan penelitian di tempat terkait, struktur organisasi Ningsih Florist dapat dilihat pada Gambar 1.

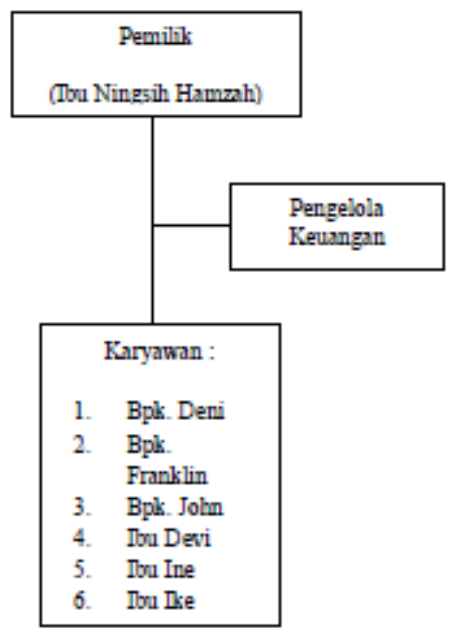

Gambar 1. Struktur Organisasi Ningsih Florist.

Gambar 1 menunjukkan bahwa struktur organisasi Ningsih Florist termasuk tipe organisasi fungsional, dimana pihak Ningsih Florist telah melakukan pembagian tugas meskipun masih tergolong sederhana.

\section{Kegiatan Produksi Rangkaian Bunga Krisan Proses Produksi Rangkaian Bunga Krisan}

Pembuatan rangkaian bunga krisan pada Ningsih Florist dilakukan sebanyak 6 kali dalam seminggu atau sekitar 26 kali dalam sebulan. Dalam penggunaan bahan baku bunga krisan dan bunga penolong lainnya disesuaikan dengan harga yang diminta konsumen. Adapun proses produksi masing-masing rangkaian bunga krisan, yaitu sebagai berikut :

1. Bunga Dada (Korsase), dalam pembuatannya membutuhkan beberapa bahan baku yaitu sejumlah tangkai bunga krisan, dan bahan penolong yaitu berupa daun pakis, sepotong tangkai lidi, selotip, peniti, dan pita. Untuk pembuatannya, bunga krisan dan daun pakis direkatkan bersama-sama menggunakan selotip, kemudian dengan cara yang sama dalam menyatukan bunga krisan dan daun pakis pada sepotong tangkai lidi yang sudah direkatkan sebuah peniti. Setelah itu bunga korsase tinggal diikat dengan rapi menggunakan pita.

2. Bunga Tangan, dalam pembuatannya membutuhkan bahan baku yaitu beberapa tangkai bunga krisan dengan bahan penolong berupa kayu berukuran kecil, oasis, tali rafia, daun pakis, kertas karton, dan pita. Untuk pembuatannya, oasis yang ukurannya sudah disesuaikan dibungkus dengan rapi menggunakan kertas karton, kemudian direkatkan pada kayu berukuran kecil menggunakan tali rafia. Setelah itu, bunga krisan dirangkai pada oasis kemudian disusul dengan sepotong pita yang sudah dibentuk menjadi sebuah model menarik, diikat pada kayu dan dirangkai diatas bunga tangan.

3. Bunga Meja, dalam pembuatannya membutuhkan bahan baku yaitu beberapa tangkai bunga krisan, dan bahan penolong berupa vas, oasis, bunga antherium, dan daun palm. Untuk pembuatannya, vas yang sudah tersedia dimasukkan sepotong oasis yang kemudian bunga dan daun yang ada tinggal dirangkaikan diatas oasis.

4. Bunga Krans, dalam pembuatannya membutuhkan beberapa tangkai bunga krisan dengan bahan penolong berupa kayu, paku, oasis, tali rafia, daun palm, dan kertas karton berwarna hitam. Untuk pembuatannya hampir sama dengan pembuatan bunga papan, yaitu dibentuk terlebih dahulu rangka bunga krans, kemudian oasis direkatkan dengan rangka menggunakan tali rafia, dimana oasis digunakan sebagai media penancapan bunga. Langkah terakhir yaitu, diletakkannya kertas karton berwarna hitam yang sudah dicetakkan ucapan duka cita.

5. Bunga Papan, dalam pembuatannya membutuhkan cukup banyak bahan baku yaitu bunga krisan, dan bahan penolong secukupnya yaitu berupa kayu, paku, oasis, tali rafia, bambu, daun palm, dan bunga antherium. Untuk pembuatannya, dibentuk terlebih dahulu sebuah rangka, kaki bunga papan dengan ukuran yang disesuaikan, kemudian baliho yang sudah tersedia dipasang kerangka dengan menggunakan 
tali rafia. Selanjutnya oasis dipasang kebagian atas dan bawah baliho lalu bunga dan daun yang telah tersedia dirangkai di oasis tersebut.

\section{Analisis Biaya}

Analisis biaya digunakan untuk menghitung biaya total usaha rangkaian bunga krisan dalam proses pembuatannya. Tujuan analisis biaya usaha rangkaian bunga krisan adalah untuk menggolongkan biaya menurut fungsi pokok dalam usaha dan menurut perilakunya dalam perubahan volume kegiatan usaha ke dalam biaya tetap dan biaya variabel dengan penjelasan sebagai berikut.

1. Biaya tetap merupakan biaya yang digunakan dalam proses produksi yang besarnya tidak dipengaruhi oleh jumlah output yang dihasilkan. Salah satu yang tergolong biaya tetap adalah biaya produksi yaitu biaya penyusutan. Setiap bulannya Ningsih Florist memiliki biaya penyusutan peralatan sebesar Rp. 46.250 selama satu kali proses produksi. Biaya penyusutan peralatan-peralatan pada Ningsih Florist telah diketahui, maka biaya penyusutan tersebut dikelompokkan dalam Biaya Tetap. Biaya tetap usaha rangkaian bunga krisan pada Ningsih Florist dapat dilihat pada Tabel 3. Biaya tetap merupakan biaya yang harus dikeluarkan berapapun jumlah yang dihasilkan.

2. Biaya Variabel terdiri dari biaya pembelian bahan baku utama dan biaya pembelian bahan tambahan penolong juga biaya tenaga kerja. Dalam hal ini biaya bahan penolong akan dikelom-pokkan per masing-masing jenis dari rangkaian bunga krisan antara lain, bunga korsase (bunga dada), bunga tangan, bunga meja, bunga krans, dan bunga papan. Jenis dan besarnya biaya variabel masing-masing rangkaian bunga yang dikeluarkan dapat dilihat pada Tabel 4.

3. Biaya total usaha rangkaian bunga krisan meliputi seluruh biaya tetap dan biaya variabel. Besarnya biaya total usaha rangkaian bunga dalam proses produksi pada bulan April dapat dilihat pada Tabel 6.

Tabel 4 menunjukkan biaya variabel pada Ningsih Florist selama proses produksi pada bulan April sebesar Rp. 49.310.015,80 dengan biaya bahan baku sebesar Rp. 15.444.000, biaya bahan penolong sebesar Rp. 23.466.015,80 yang terdiri dari biaya bahan penolong bunga korsase (dada) sebesar Rp. 357.015,80, biaya bahan penolong bunga tangan sebesar Rp. 386.000, biaya bahan penolong bunga meja sebesar Rp. 3.050.000, biaya bahan penolong bunga krans sebesar Rp. 307.000, biaya bahan penolong bunga papan sebesar Rp. 19.366.000, dan biaya tenaga kerja 8 orang sebesar Rp. 10.400.000 yang didapat dari perkalian jumlah hari kerja yaitu 26 hari dalam sebulan dikali dengan upah per harian sebesar Rp. 50.000.

Setiap bulannya Ningsih Florist memiliki biaya penyusutan peralatan sebesar $\mathrm{Rp}$. 46.250 selama satu kali proses produksi.

Biaya penyusutan peralatan-peralatan pada Ningsih Florist telah diketahui, maka biaya penyusutan tersebut dikelompokkan dalam Biaya Tetap. Biaya tetap usaha rangkaian bunga krisan pada Ningsih Florist dapat dilihat pada Tabel 3 .

Tabel 1. Besar Biaya Penyusutan Usaha Rangkaian Bunga Krisan per Satuan Jenis Alat pada Ningsih Florist

\begin{tabular}{llllllc}
\hline No. & Jenis Alat & Jumlah Alat & $\begin{array}{l}\text { Nilai Akhir } \\
(\mathrm{Rp})(\text { bulan) }\end{array}$ & $\begin{array}{l}\text { Umur } \\
\text { Ekonomis }\end{array}$ & $\begin{array}{l}\text { Nilai Awal } \\
(\mathrm{Rp})\end{array}$ & $\begin{array}{l}\text { Penyusutan } \\
\text { (Rp/Produksi) }\end{array}$ \\
\hline 1. & Gunting & 1 & 50.000 & 2 & 15.000 & 17.500 \\
2. & Parang & 1 & 150.000 & 5 & 25.000 & 25.000 \\
3. & Gergaji & 1 & 100.000 & 1 & 15.000 & 85.000 \\
\hline Jumlah & & & 300.000 & & 55.000 & 127.500 \\
\hline
\end{tabular}

Sumber : Hasil Analisis Data Primer 


\section{Analisis Penerimaan Usaha Rangkaian Bunga Krisan pada Ningsih Florist selama Satu Kali Proses Produksi pada Bulan April 2015.}

Penerimaan usaha rangkaian bunga krisan dihitung dari jumlah produksi yang dihasilkan dikalikan dengan harga. Penerimaan usaha rangkaian bunga krisan pada Ningsih Florist dapat dilihat pada Tabel 6.

\section{Analisis Nilai Tambah Bahan Baku Rangkaian Bunga Krisan}

Analisis nilai tambah usaha rangkaian bunga krisan dilakukan untuk mengetahui besarnya nilai yang ditambahkan pada bahan baku yang digunakan dalam memproduksi rangkaian bunga krisan. Perhitungan analisis nilai tambah rangkaian bunga krisan pada Ningsih Florist selama satu kali proses produksi pada bulan April 2015 dapat dilihat pada Tabel 7.

Tabel 7 menunjukkan analisis nilai tambah yang meliputi nilai tambah bruto, nilai tambah netto, nilai tambah per tenaga kerja dari Ningsih Florist.

1. Nilai tambah bruto merupakan dasar dari perhitungan nilai tambah netto dan nilai tambah per bahan baku. Nilai tambah bruto sebesar Rp. 16.729.984,20 diperoleh dari nilai produk akhir sebesar Rp. $\quad 66.040 .000$ dikurangi biaya antara sebesar Rp. 49.310.015,80.

2. Nilai tambah netto pada Ningsih Florist sebesar Rp. 16.683.734,20 diperoleh dari nilai tambah bruto sebesar Rp. 16.729.984,20 dikurangi dengan nilai akhir peralatan dan dibagi dengan umur ekonomis dalam bulan yaitu sebesar Rp. 46.250.

3. Nilai tambah per bahan baku merupakan ukuran untuk mengetahui produktivitas bahan baku yang dapat dimanfaatkan untuk menghasilkan rangkaian bunga krisan. Nilai tambah per bahan baku rangkaian bunga krisan pada Ningsih Florist sebesar Rp. 3.249,80/tgk, artinya untuk setiap satu tangkai bahan baku rangkaian bunga krisan yang digunakan dalam produksi memberikan nilai tambah bahan baku sebesar Rp. 3.249,80. Besarnya nilai tambah tersebut diperoleh dari nilai tambah bruto sebesar Rp. 16.729.984,20 dibagi dengan jumlah bahan baku yang digunakan yaitu sebanyak 5.148 tangkai.

\section{Perhitungan Nilai Tambah per Satu item Jenis Rangkaian Bunga}

Selain perhitungan nilai tambah per satu kali produksi selama 1 bulan, berikut ini merupakan rincian biaya dasar produksi sekaligus nilai tambah per 1 item rangkaian bunga.

\section{Bunga Korsase}

1 item bunga korsase memakai 2 tangkai bunga krisan, Biaya dasar 1 item bunga korsase :

Bunga krisan $=2 \times$ Rp. $3.000=$ Rp. 6.000

Bahan penolong $=$ Rp. 357.015,80:260 = Rp. 1.373/1 korsase, Tenaga kerja $=$ Rp. $50.000: 8$ jam kerja $=$ Rp. 6.250/jam, Waktu produksi (jam) $= \pm 1 / 2$ jam $=$ Rp. 3.125, Biaya penyusutan $=$ Rp. $46.250: 598$ item $=$ Rp. 78 Jadi, Rp. 6000 + Rp. 1.373 + Rp. 3.125 + Rp. $78=$ Rp. Rp. 10.576 sebagai biaya dasar rangkaian bunga korsase. Harga jual 1 item bunga korsase Rp. 15.000. Rp. 15.000 - Rp. $10.576=$ Rp. 4.424 sebagai nilai tambah per 1 item bunga korsase. 1 bulan bunga korsase memberikan nilai tambah sebesar \pm Rp. 1.150.240.

2. Bunga Tangan

1 item bunga tangan memakai 8 tangkai bunga krisan, Biaya dasar 1 item bunga tangan : Bunga krisan $=8 \times$ Rp. $3.000=$ Rp. 24.000 Bahan penolong $=$ Rp. $386.000: 52$ item $=\mathrm{Rp}$. 7.423/1 bunga tangan, Tenaga kerja $=\mathrm{Rp}$. $50.000: 8$ jam kerja = Rp. 6.250/jam, Waktu produksi $= \pm 1$ jam $=$ Rp. 6.250, Biaya penyusutan $=$ Rp. 78 Jadi, Rp. $24.000+$ Rp. $7.423+$ Rp. $6.250+$ Rp. $78=$ Rp. 37.751 sebagai biaya dasar rangkaian bunga tangan. Harga jual 1 item bunga tangan Rp. 250.000. Rp. $250.000-$ Rp. $37.751=$ Rp. 212.249 sebagai nilai tambah per 1 item bunga tangan. Dalam 1 bulan bunga tangan memberikan nilai tambah sebesar \pm Rp. 11.036.948.

\section{Bunga Meja}

1 item bunga meja memakai 7 tangkai bunga krisan Biaya dasar 1 item bunga meja :

Bunga krisan $=7$ x Rp. $3.000=$ Rp. 21.000, Bahan penolong $=$ Rp. $3.050 .000: 182$ item $=$ Rp. 16.758/1 bunga meja, Tenaga kerja $=\mathrm{Rp}$. $50.000: 8$ jam kerja = Rp. 6.250/jam, Waktu produksi $= \pm 1$ jam $=$ Rp. 6.250, Biaya 
Penyusutan = Rp. 78. Jadi, Rp. $21.000+$ Rp. $16.758+$ Rp. $6.250+$ Rp. $78=$ Rp. 44.086 sebagai biaya dasar rangkaian bunga meja. Harga jual 1 item bunga meja Rp. 45.000. Rp. 45.000 - Rp. $44.086=$ Rp. 914 sebagai nilai tambah per 1 item bunga meja. Dalam 1 bulan bunga meja memberikan nilai tambah sebesar \pm Rp. 166.348 .

4. Bunga Krans

1 bunga krans memakai 14 tangkai bunga krisan, Biaya dasar 1 item bunga krans :

Bunga krisan, $=14 \times$ Rp. $3.000,=$ Rp. 42.000, Bahan penolong $=$ Rp. $307.000: 26$ item $=$ Rp. 11.807/1 bunga krans, Tenaga kerja $=\mathrm{Rp}$. $50.000: 8$ jam kerja $=$ Rp. 6.250/jam, Waktu produksi $= \pm 2$ jam $=$ Rp. 12.500, Biaya penyusutan $=$ Rp. 78, Jadi, Rp. 42.000 + Rp. $11.807+$ Rp. $12.500+$ Rp. $78=$ Rp. 66.385 sebagai biaya dasar rangkaian bunga krans. Harga jual 1 item bunga krans Rp. 75.000. Rp. 75.000 - Rp. 66.385 = Rp. 8.615 sebagai nilai tambah per 1 item bunga krans.
Dalam 1 bulan bunga krans memberikan nilai tambah sebesar \pm Rp. 223.990 .

5. Bunga Papan

1 bunga papan memakai 33 tangkai bunga krisan, Biaya dasar 1 item bunga papan :

Bunga krisan $=33 \times$ Rp. $3.000=R p$. 99.000

Bahan Penolong $=$ Rp. 19.366.000 : 78 item = Rp. 248.282/1 bunga papan, Tenaga kerja $=$ Rp. $50.000: 8$ jam kerja $=$ Rp. 6.250/jam

Waktu produksi $= \pm 3$ jam $\times 2$ org TK $=$ Rp. 37.500

Biaya Penyusutan $=$ Rp. 78, Jadi, Rp. $99.000+$ Rp. $248.282+$ Rp. $37.500+$ Rp. 78 $=$ Rp. 384.860 sebagai biaya dasar rangkaian bunga papan. Harga jual 1 item bunga papan Rp. 500.000. Rp. $500.000-$ Rp. $384.860=$ Rp. 115.140 sebagai nilai tambah per 1 item bunga papan. Dalam 1 bulan bunga papan memberikan nilai tambah sebesar Rp. 8.980.920.

Tabel 2. Besar Biaya Penyusutan Usaha Rangkaian Bunga Krisan pada Ningsih Florist Selama Satu Kali Proses Produksi pada Bulan April 2015

\begin{tabular}{lllllll}
\hline No. & Jenis Alat & $\begin{array}{l}\text { Jumlah } \\
\text { Alat }\end{array}$ & $\begin{array}{l}\text { Nilai } \\
\text { Akhir (Rp) }\end{array}$ & $\begin{array}{l}\text { Umur } \\
\text { Ekonomis } \\
\text { (bln) }\end{array}$ & $\begin{array}{l}\text { Nilai } \\
\text { Awal } \\
(\mathrm{Rp})\end{array}$ & $\begin{array}{l}\text { Penyusutan } \\
\text { (Rp/produksi) }\end{array}$ \\
\hline 1. & Gunting & 10 & 500.000 & 2 & 150.000 & 175.000 \\
2. & Parang & 5 & 750.000 & 5 & 125.000 & 125.000 \\
3. & Gergaji & 3 & 300.000 & 1 & 45.000 & 255.000 \\
\hline
\end{tabular}

Jumlah

Sumber : Hasil Analisis Data Primer

Tabel 3. Biaya Tetap Usaha Rangkaian Bunga Krisan pada Ningsih Florist Selama Proses Produksi pada Bulan April 2015

\begin{tabular}{clrr}
\hline No. & \multicolumn{1}{r}{ Jenis Biaya Tetap } & Biaya per Bulan (Rp) & Biaya per Tahun (Rp) \\
\hline 1. & PBB & 50.000 & 600.000 \\
2. & Penyusutan & 46.250 & 555.000 \\
3. & Listrik & 1.000 .000 & 12.000 .000 \\
4. & Telepon & 250.000 & 3.000 .000 \\
5. & Sewa tempat & 1.250 .000 & 15.000 .000 \\
\hline & Jumlah & 2.596 .250 & 31.155 .000 \\
\hline
\end{tabular}

Sumber : Hasil Analisis Data Primer 
Tabel 4. Jenis dan Besar Biaya Variabel Rangkaian Bunga Krisan pada Ningsih Florist Selama Proses Produksi pada Bulan April 2015

\begin{tabular}{|c|c|c|c|c|c|}
\hline No. & Jenis Bahan Baku & Satuan & Fisik & $\begin{array}{l}\text { Harga/Satuan } \\
(\mathrm{Rp})\end{array}$ & Jumlah (Rp) \\
\hline \multirow[t]{11}{*}{1.} & Bunga Korsase (Dada) : & & & & \\
\hline & Bunga Krisan : & $\operatorname{tgk}$ & 520 & 3.000 & 1.560 .000 \\
\hline & Bunga Tangan : & & & & \\
\hline & Bunga Krisan : & $\operatorname{tgk}$ & 416 & 3.000 & 1.248 .000 \\
\hline & Bunga Meja : & & & & \\
\hline & Bunga Krisan : & $\operatorname{tgk}$ & 1.274 & 3.000 & 3.822 .000 \\
\hline & Bunga Krans : & & & & \\
\hline & Bunga Krisan : & $\operatorname{tgk}$ & 364 & 3.000 & 1.092 .000 \\
\hline & Bunga Papan: & & & & \\
\hline & Bunga Krisan : & $\operatorname{tgk}$ & 2.574 & 3.000 & 7.722 .000 \\
\hline & Jumlah & & & & 1.000 \\
\hline \multirow[t]{30}{*}{2.} & $\begin{array}{l}\text { Biaya Bahan Penolong: } \\
\text { Bunga Korsase (Dada) : }\end{array}$ & & & & \\
\hline & Peniti & pcs & 260 & 83,33 & $21,665,8$ \\
\hline & Selotip & pcs & 1 & 6.000 & 6.000 \\
\hline & Pita & pcs & 260 & 5.00 & 130.000 \\
\hline & Daun pakis & $\operatorname{tgk}$ & 65 & 3.000 & 195.000 \\
\hline & Lidi & $\operatorname{tgk}$ & 87 & 50 & 4.350 \\
\hline & Jumlah & & & & $357.015,80$ \\
\hline & Bunga Tangan & & & & \\
\hline & ayu & $\mathrm{mtr}$ & 2 & 10.000 & 20.000 \\
\hline & Oasis & pcs & 18 & 3.000 & 54.000 \\
\hline & Tali rafia & $\mathrm{kg}$ & $1 / 4$ & 6.000 & 6.000 \\
\hline & Daun pakis & $\operatorname{tgk}$ & 52 & 3.000 & 156.000 \\
\hline & Kertas karton & lbr & 52 & 1.500 & 78.000 \\
\hline & Pita & pcs & 18 & 4.000 & 72.000 \\
\hline & Jumlah & & & & 386.000 \\
\hline & Bunga meja : & & & & \\
\hline & Vas & $\mathrm{pcs}$ & 182 & 3.000 & 546.000 \\
\hline & Oasis & $\mathrm{pcs}$ & 46 & 3.000 & 138.000 \\
\hline & Bunga antherium & $\operatorname{tgk}$ & 910 & 2.500 & 2.275 .000 \\
\hline & Daun palm & $\operatorname{tgk}$ & 182 & 500 & 91.000 \\
\hline & Jumlah & & & & 3.050.000 \\
\hline & Bunga Krans : & & & & \\
\hline & Kayu & $\mathrm{mtr}$ & 4 & 10.000 & 40.000 \\
\hline & Paku & $\mathrm{kg}$ & 1 & 20.000 & 20.000 \\
\hline & Oasis & pcs & 9 & 3.000 & 27.000 \\
\hline & Tali rafia & $\mathrm{kg}$ & $1 / 2$ & 12.000 & 12.000 \\
\hline & Daun palm & $\operatorname{tgk}$ & 78 & 5.00 & 39.000 \\
\hline & Kertas karton hitam & $\mathrm{lbr}$ & 26 & 1.500 & 39.000 \\
\hline & Print & lbr & 26 & 5.000 & 130.000 \\
\hline & Jumlah & & & & 19.366 .000 \\
\hline \multirow[t]{2}{*}{3.} & $\begin{array}{l}\text { Biaya Tenaga Kerja } \\
\text { Total Biaya Bahan Penolong }\end{array}$ & org & 8 & 1.300 .000 & $\begin{array}{r}10.400 .000 \\
\mathbf{2 3 . 4 6 6 . 0 1 5 , 8 0}\end{array}$ \\
\hline & Total Biaya Variabel & & & & 49.310.015,80 \\
\hline
\end{tabular}

Sumber : Hasil Analisis Data Primer 
Tabel 5. Biaya Total Usaha Rangkaian Bunga Krisan pada Ningsih Florist Selama Proses Produksi pada Bulan April 2015

\begin{tabular}{|c|c|c|}
\hline No & Jenis Biaya & Jumlah (Rp/Produksi) \\
\hline 1 & Biaya Tetap & 2.596 .250 \\
\hline 2 & Biaya Variabel & $49.310 .015,80$ \\
\hline & Biaya Total & $51.906 .265,80$ \\
\hline
\end{tabular}

Sumber : Hasil Analisis Data Primer

Tabel 6. Penerimaan Usaha Rangkaian Bunga Krisan pada Ningsih Florist Selama Proses Produksi pada Bulan April 2015

\begin{tabular}{clrrr}
\hline No & \multicolumn{1}{c}{ Jenis } & Fisik & Harga/Satuan $(\mathrm{Rp})$ & \multicolumn{1}{c}{ Jumlah $(\mathrm{Rp})$} \\
\hline 1 & Bunga Korsase & 260 & 15.000 & 3.900 .000 \\
2 & Bunga Tangan & 52 & 250.000 & 13.000 .000 \\
3 & Bunga Meja & 182 & 45.000 & 8.190 .000 \\
4 & Bunga Krans & 26 & 75.000 & 1.950 .000 \\
5 & Bunga Papan & 78 & 500.000 & 39.000 .000 \\
\hline Total Penerimaan & & & 66.040 .000 \\
\hline
\end{tabular}

Tabel 7. Analisis Nilai Tambah Bunga Krisan menjadi Rangkaian Bunga Ningsih Florist Selama Satu Kali Proses Produksi pada Bulan April 2015

\begin{tabular}{llr}
\hline No & \multicolumn{1}{c}{ Uraian } & Jumlah \\
\hline 1 & Nilai Produk Akhir (Rp) & 66.040 .000 \\
2 & Biaya Bahan Baku (Rp) & 15.444 .000 \\
3 & Jumlah Bahan Baku (Tgk) & 5.148 \\
4 & Biaya Bahan Penolong (Rp) & $23.466 .015,80$ \\
5 & Biaya Tenaga Kerja & 10.400 .000 \\
6 & Biaya Antara (Rp) & $49.310 .015,80$ \\
7 & Nilai Penyusutan (Rp) & 46.250 \\
8 & Nilai Tambah Bruto (Rp) & $16.729 .984,20$ \\
9 & Nilai Tambah Netto (Rp) & $16.683 .734,20$ \\
10 & Nilai Tambah per Bulan Bahan Baku (Rp/Tgk) & $3.249,80$ \\
\hline
\end{tabular}

Sumber : Hasil Analisis Data primer

\section{KESIMPULAN DAN SARAN}

\section{Kesimpulan}

Bunga krisan yang dirangkai menjadi beberapa rangkaian bunga menghasilkan berbagai nilai tambah yaitu Nilai Tambah Bruto Rp. 16.729.984,20, Nilai Tambah Netto Rp. 16.683.734,20, Nilai Tambah per Bahan Baku Rp. 3.249,80/tgk.Adapun nilai tambah yang dihitung per satu item rangkaian bunga dimana bunga korsase memberikan nilai tambah sebesar Rp. 4.424/ item, bunga tangan Rp. 212.249/ item, bunga meja Rp. 914/ item, bunga krans Rp. 8.615/ item, dan bunga papan Rp. 115.140/ item.
Saran

Saran yang dapat diberikan berdasarkan hasil penelitian yang telah dilakukan mengenai nilai tambah bunga krisan pada Ningsih Florist adalah :

1. Berdasarkan hasil penelitian bahwa rangkaian bunga krisan pada Ningsih Florist menghasilkan nilai tambah, usaha ini layak untuk dikembangkan. Maka disarankan agar Ningsih Florist bisa mengembangkan usahanya salah satu dengan cara membuka cabang florist ditempat lain.

2. Disarankan agar penelitian terkait hal ini dapat dikembangkan oleh peneliti selanjutnya. 


\section{DAFTAR PUSTAKA}

AAK, 1990. Budi Daya Tanaman Padi. Aksi Agraris Kanisius. Yogyakarta: Yayasan Kanisius.

Amat Muhyidin, 2010. Analisis Efisiensi Penggunaan Faktor-Faktor Produksi Pada Usaha Tani Padi Di Kecamatan Pekalongan Selatan.

Http://Eprints.Uns.Ac.Id/5683/1/135380908 201010471.Pdf. diakses pada tanggal 29 Januari 2015

Budi, Kurniawan. 2007. Teknik Bercocok Tanam Padi. Penebar Swadaya. Jakarta.

Damayanti, F. 2007. Analisis Pendapatan Dan Efisiensi Produksi Usahatani Padi Sawah (Studi Kasus Di Desa Purwodadi Kecamatan Trimurjo Kabupaten Lampung Tengah). Skripsi. Fakultas Pertanian. Institut Pertanian Bogor.

Nugraha Setiawan. Penentuan Ukuran Sampel Memakai Rumus Slovin dan Tabel KrejcieMorgan: Telaah Konsep dan Aplikasinya. http://pustaka.unpad.ac.id/wpcontent/upload s/2009/03/penentuan_ukuran_sampel_mem akai_rumus_slovin.pdf. diakses pada tanggal 06 Februari 2015.

Rahim. Abd. dan Hastuti. Drw. 2007. Ekonomi Pertanian. Penebar Swadaya, Jakarta

Sudarman. 2001. Teori Ekonomi Mikro. Pusat Penerbitan Universitas Terbuka,Jakarta

Soekartawi, A., Soeharjo, Dillon, J. L., Hardaker, J. B., 1986. Ilmu Usaha Tani Dan Penelitian Untuk Pengembangan Petani Kecil. Grafindo Persada. Jakarta Soeharjo Dan Patong (1973)
Soekartawi. 2002. Analisis Usahatani. Penerbit Universitas Indonesia (Ui- Press), Jakarta. . 2002. Ilmu Usahatani Dan Penelitian Untuk Pengembangan Petani Kecil, Universitas Indonesia. Press, Jakarta. . 2002. Prinsip Dasar Ilmu Ekonomi Pertanian: Teori Dan Aplikasi. Jakarta: Raja Grafindo Persada.

Sukirno, Sadono. 2000. Mikro Ekonomi Modern: Perkembangan Pemikiran Dari Klasik Sampai Keynesian Baru, Edisi 1. Pt Raja Grafindo, Jakarta 2006. Pengantar Teori Mikro Ekonomi. Penerbit : Pt Raja Grafindo, Jakarta

Supartama Made, 2013. Analisis Pendapatan dan Kelayakan Usahatani Padi Sawah Di Subak Baturiti Desa Balinggi Kecamatan Balinggi Kabupaten Parigi Moutong.Https://Ml.Scribd.Com/Doc/20555 1759/Analisis-Pendapatan-Dan-KelayakanUsahatani-Padi. diakses pada tanggal 29 Januari 2015.

Yanti. 2012. Analisis Pendapatan Petani Kelapa Di Kecamatan Saliabu Kabupaten Talaud. Skripsi, Universitas Sam Ratulangi Manado Hal. 14 Wonda. 2012.

Zulkarnain Iskandar, 2004. Analisis Produksi dan Keuntungan Pada Usahatani Padi Sawah Jawa Tengah. Tesis. Program Pascasarjana Universitas Diponegoro. 